Oliveira, V. \& Leal, S. (2016). O efeito mediador da motivação intrínseca na relação entre as características da função e o desempenho individual. VI Conferência em Investigação e Intervenção em RH. 18 e 19 de fevereiro de 2016. Escola Superior de Ciências Empresariais (ESCE) do Instituto Politécnico de Setúbal (IPS). http://www.eseig.ipp.pt/conferencias/index.php/iirh/viconferencia-ii (Abstract)

\title{
O efeito mediador da motivação intrínseca na relação entre as características da função e o desempenho individual
}

Vanessa Oliveira

vanessa oliveira089@sapo.pt

\author{
Susana Leal \\ Instituto Politécnico de Santarém e Centro de Investigação em Qualidade de Vida
}

susana.leal@esg.ipsantarem.pt

\section{Resumo}

Objetivo. Este trabalho testa empiricamente como as perceções acerca das características da função explicam o desempenho individual, tanto diretamente quanto através da mediação da motivação intrínseca. As características da função estudadas abarcam a variedade de trabalho, a autonomia, o feedback, a relação com os outros, a identidade da tarefa e a amizade no local de trabalho (Sims, Szilagyi e Keller, 1976). Embora seja profícua a investigação que considera estes constructos, é menos frequente aquela que: (a) os considera em simultâneo, (b) testa a evidência empírica em Portugal, e (c) considera tanto o desempenho individual autoreportado como o avaliado pelas chefias.

Metodologia. A amostra abarca 153 colaboradores (95\% do género feminino, 56\% com o 9. ano de escolaridade, $27 \%$ com o secundário e $17 \%$ com um curso superior, $9 \%$ desempenham funções de chefia) provenientes de cinco Instituições Particulares de Solidariedade Social. A idade média dos inquiridos cifra-se nos 43,2 anos (DP: 9,6) e a antiguidade média em 10,2 anos (DP: 8,4). As características da função foram medidas com a escala de Sims et al. (1976), a motivação intrínseca através da escala de Warr, Cook e Wall (1979) e o desempenho individual através da escala de Welbourne, Jonhson e Erez (1998). Os dados foram submetidos análises fatoriais exploratórias. Analisou-se a consistência interna das escalas e prosseguiu-se com análises de médias, correlações e regressões lineares hierárquicas. O efeito mediador da motivação intrínseca foi testado através do Teste de Sobel.

Resultados. Os dados sugerem o seguinte: (a) a motivação intrínseca medeia totalmente a relação entre as características da função e o desempenho autoreportado, não ocorrendo o mesmo efeito mediador com o desempenho avaliado pelas chefias; (b) as características da função influenciam direta e positivamente a motivação intrínseca e o desempenho reportado pelas chefias; (c) a motivação intrínseca afeta positivamente o desempenho autoreportado. Emergem diferenças significativas entre a autoavaliação de desempenho e a respetiva avaliação pelas chefias, o que surpreende. Aprofundou-se o estudo para aferir a razão de tal diferença.

Contributo. O presente estudo contribui para compreender como as características da função influenciam a motivação intrínseca das pessoas no trabalho e o seu desempenho individual.

Limitações. O desempenho individual foi medido através de uma medida subjetiva pelo que estudos futuros devem privilegiar medidas de desempenho objetivas. A relação entre os 
Oliveira, V. \& Leal, S. (2016). O efeito mediador da motivação intrínseca na relação entre as características da função e o desempenho individual. VI Conferência em Investigação e Intervenção em RH. 18 e 19 de fevereiro de 2016. Escola Superior de Ciências Empresariais (ESCE) do Instituto Politécnico de Setúbal (IPS). http://www.eseig.ipp.pt/conferencias/index.php/iirh/viconferencia-ii (Abstract)

constructos e a medida de desempenho autoreportado pode padecer de problemas atinentes à variância do método comum. 